\title{
Comments on Case Report-Post B-Lynch Uterine Rupture: Case Report and Review of Literature
}

\author{
Singhal Savita Rani
}

Received: 16 December 2014/ Accepted: 28 December 2014/Published online: 21 January 2015

(C) Federation of Obstetric \& Gynecological Societies of India 2015

\section{Dear Editors,}

I read with interest the article 'Post B-Lynch Uterine Rupture: Case Report and review of Literature' by Date S et al. published in September-October 2014 issue. Mechanical uterine compression sutures are hysterectomy saving emergency procedure for atonic post partum hemorrhage and these are quite safe with minimal complications. B-Lynch suture was first reported in 1997 in which two parallel sutures are applied, starting from just above the bladder reflection, and are tied after taking over the fundus of the uterus from posterior wall [1]. As mentioned by the authors, there is one case report of spontaneous uterine rupture at 32 weeks after B-Lynch suture where PDS suture was used [2]. After reviewing that case, it is seen that the site of rupture was vertical, at the fundus on left lateral side, and a deep vertical groove was present on posterior wall, which is the position of the compression suture which might have eroded the uterus thus leading to weakening of myometrium.

The case reported by the authors Date $\mathrm{S}$ et al. is 23-yearold G4P1L1A2 with uterine rupture at four month of gestation. As clear from the figure, the rupture is transverse and at fundus of uterus [3]. It is pertinent to note that this

Singhal S. R. (凹), Professor

Department of Obstetrics and Gynecology, Post Graduate Institute of Medial Sciences, 14/8FM, Medical Campus, Rohtak

124001, Haryana, India

e-mail: savita06@gmail.com patient is also having history of two abortions. In this patient, other causes of rupture could be either weakening of myometrium due to the evacuation of the uterus for abortions or some uterotonic drug given for illegal abortion in second trimester, which is still common in India. Taking into account the transverse fundal rupture that too at 4 months of gestation the other causes of uterine rupture should be ruled out before labeling B-Lynch suture (which is quite safe and has minimal complications) as a cause for uterine rupture.

Conflict of interest Certified that there are no conflicts of interest and financial disclosure.

\section{References}

1. Lynch CB, Coker A, Lawal A, et al. The B-Lynch surgical technique for the control of massive postpartum haemorrhage: an alternative to hysterectomy? Five cases reported. Br J Obstet Gynecol. 1997; 104(3):372-5.

2. Pechtor K, Richards B, Paterson H. Antenatal catastrophic uterine rupture at 32 weeks of gestation after previous B-Lynch suture. BJOG. 2010;117:889-91.

3. Date S, Murthy B, Megdam A. Post B-Lynch uterine rupture: case report and review of literature. J Obstet Gynecol India. 2014; 64(5):362-3. 